\title{
Pes muscles and their action in giant anteater Myrmecophaga tridactyla (Myrmecophagidae, Pilosa) compared with other plantigrade mammals
}

\author{
Petr P. Gambaryan, Olga V. Zherebtsova, Anna A. Perepelova \\ \& Vladimir V. Platonov
}

\begin{abstract}
The pes myology of the giant anteater Myrmecophaga tridactyla has been studied in detail to understand its adaptive properties. The morphofunctional features of these muscles have been compared to the respective muscles of the brown bear (Ursus arctos), in which the locomotor role of the foot is similar to that in the giant anteater. M. tridactyla has a complete set of short pes muscles and their structure is generally the same as in the brown bear and some other plantigrade mammals. In spite of some differences, the work of the pes muscles in the giant anteater and brown bear is basically similar, which is consistent with the similar anatomy of these muscles in these two mammals. This similarity suggests that the pes myology in the animals studied reflects the adaptation to the run, which in the giant anteater is however less pronounced than in the brown bear.
\end{abstract}

KEY WORDS: Myrmecophaga tridactyla, Ursus arctos, pes muscles, adaptive features, morphofunctional analysis.

Petr P. Gambaryan [gambar@PG15104.spb.edu], Zoological Institute, Russian Academy of Sciences, Universitetskaya nab. 1, Saint Petersburg 199034, Russia; Olga V. Zherebtsova [hedgol@yandex.ru], Zoological Institute, Russian Academy of Sciences, Universitetskaya nab. 1, Saint Petersburg 199034, Russia; Anna A. Perepelova [kungsgatan@mail.ru], State Pedagogical University, Nab. reki Moiki 48, Saint Petersburg 191186, Russia; Vladimir V. Platonov [vladimirplatonov@mail.ru] Zoological Institute, Russian Academy of Sciences, Universitetskaya nab. 1, Saint Petersburg 199034, Russia.

\section{Мышцы стопы и их работа у гигантского муравьеда Myrmecophaga tridactyla (Myrmecophagidae, Pilosa) по сравнению с другими стопоходящими млекопитающими}

\section{П.П. Гамбарян, О.В. Жеребцова, А.А. Перепелова, В.В. Платонов}

РЕЗЮМЕ. Для выяснения адаптивных особенностей мышц стопы гигантского муравьеда Myrmecophaga tridactyla проведено детальное изучение их строения, а также сравнение морфо-функциональных особенностей этих мышц с аналогичной мускулатурой бурого медведя (Ursus arctos), локомоторная роль стопы которого наиболее близка таковой муравьеда. Для M. tridactyla характерен довольно полный набор коротких мышц стопы. Аналогичные мышцы во многом со сходным строением наблюдаются и в стопе бурого медведя, а также некоторых других стопоходящих млекопитающих. Несмотря на некоторые различия, работа мышц, действующих на стопу, у гигантского муравьеда и бурого медведя также в основном сходна, что согласуется с общими чертами анатомии этих мышц. Наблюдаемое сходство позволяет предположить, что миология стопы у изученных животных несет отпечаток адаптации к бегу, которая, однако, у муравьеда выражена слабее, чем у медведя.

КЛЮЧЕВЫЕ СЛОВА: Myrmecophaga tridactyla, Ursus arctos, мышцы стопЫ, адаптивные особенности, морфо-функциональный анализ.

\section{Introduction}

The giant anteater (Myrmecophaga tridactyla) is a typical terrestrial plantigrade mammal. When running, the plantigrade mammals touch the ground first by its heel and then by its toes. The change of load upon the pes during the phases of foothold and transfer is provid- ed mainly by short pes muscles and also by long crus muscles which are inserted on the foot. The functional morphology of these muscles is of special interest to clarify the adaptive evolution of the giant anteater. The locomotor role of the foot in the brown bear is similar to that in the giant anteater. However, information about the structure, functioning and coordination of the mus- 
culature responsible for the mobility of the pes in these animals is scarce (especially about the giant anteater) and insufficient to understand the work of their foot in different types of locomotion (Cuvier, 1849; Windle \& Parsons, 1898, 1899; McMurrich, 1907; Hildebrand, 1988; Lewis, 1989). Therefore, our research has been concerned with the comparative morphofunctional analysis of the pes muscles in the giant anteater, the brown bear, and some other plantigrade mammals with implications to their locomotor adaptations.

\section{Material and methods}

We dissected the hindlimbs of two $5 \%$ formalinfixed adult specimens of Myrmecophaga tridactyla and one hindlimb of Ursus arctos used for comparison. To better distinguish the fiber direction and connective tissue, the low-concentration aqueous solution of specific stain for myosin - Cresil fast Violet — was periodically applied for a 10-15 minutes and then rinsed out under a strong water stream. As a result the stain was washed out from the connective tissue but persisted in muscular fibers and thus highlighted the structure and disposition of the muscles.

\section{Results}

\section{The short muscles of the pes}

\section{The dorsal muscles}

M. extensor digitorum brevis in $M$. tridactyla arises from the dorsal surface of the os calcaneus (Fig. 1A). The area of insertion extends more distal than the tip of the tuber calcanei occupying one sixth of the bone length on its lateral side and two thirds on the medial one. The origin of the muscle passes also on the base of the talus joint capsule and on the dorsal surface of the tarsalia IV+V (cuboid) — tarsalia I. The muscle tendinous interface is bandaged to the connective tissue laminas which rise from the inter-metatarsal spaces extending almost up to the distal ends of the metatarsal bones. Four separate tendons of the $\mathrm{m}$. ext. digitorum longus are adjacent to the muscle middle part. M. ext. digitorum brevis ends in five tendons. Four of them are fused with the superficial lying tendons of the m. ext. digitorum longus, then pass forward to the four lateral digits and are inserted on their ungual phalanxes. The fifth tendon passes to the first digit up to the level of its first phalanx where it inserts onto the internal side of the terminal tendon of the m. ext. hallucis longus and runs with the latter to the ungual phalanx.

M. ext. digitorum brevis in $U$. arctos arises also from the dorsal surface of the os calcaneus, more distal than the articulation with the os talus passing partly on the joint capsule of the articulation with the os tibia (Fig. 1B). Four separate fusiform venters extend from the origin and end in four tendons to the medial digits.
The first of them reaches the lateral surface of the proximal end of the second phalanx of the fourth digit where it widens and fuses with the tendon of the m. ext. digitorum longus, coming from the dorsal side. Then the tendon goes straight the lateral side of the second phalanx and merges again with the tendon of the $\mathrm{m}$. extensor digitorum longus which passes independently from the medial side to the ungual phalanx. Before this phalanx, the tendons fuse again and insert on the whole dorsal surface of the ungual phalanx. The second venter runs the same way on the 3rd digit. The third venter fuses via a tendon with the $\mathrm{m}$. ext. digitorum longus on the middle part of the first phalanx of the second digit. Another half-separated venter attaches to the tendon of the m. ext. hallucis longus.

\section{The plantar muscles}

M. flexor digitorum brevis in $M$. tridactyla originates from the plantar surface of the calcaneus receding about one third of its length from the apex of the tuber calcanei (Fig. 2A). On the medial and lateral sides of the calcaneus, the muscle insertion extends proximally for more than one sixth of its length. In the middle of the pes the muscle divides into three venters that form tendons distributed to three middle digits. Then each tendon divides into two slips at the level of metatarsophalangeal junctions and is inserted on the corresponding sesamoids. There are no more distal extensions of these tendons.

M. flex. digitorum brevis in $U$. arctos, unlike in $M$. tridactyla, does not insert on the calcaneus but arises as the continuation of m. plantaris. Shortly after the origin, the muscle divides into four tendons of which the most medial has muscular fibers. The tendons are distinguished in the plantar aponeurosis by their finer edges. At the level of metatarso-phalangeal articulations, the tendons divide into two slips which aggregate again deeper than the upper running tendons of $\mathrm{m}$. flex. digitorum longus. Then they extend as double tendinous fibers along the plantar surface of the first phalanx of each lateral digit (Fig. 3A). It is noteworthy that in man, like in $M$. tridactyla, $\mathrm{m}$. flex. digitorum brevis originates from the lateral surface of the calcaneus and the insertion is into three middle digits (Sinelnikov, 1952).

The mm. abductor digiti quinti, abductor metatarsi $\mathrm{V}$ and flex. digiti quinti brevis arise together from the dorsolateral surface of $\mathrm{m}$. flex. digitorum brevis crossing obliquely its origin (Fig. 2). The muscles are separated by fibrous tissue that is evidence for their independence.

1. M. flexor digiti quinti brevis in M. tridactyla originates on the dorsal surface of the lateral venter of $\mathrm{m}$. flex. digitorum brevis from its middle and almost up to the distal quarter of the venter length (Fig. 2). Then the muscular venter of $m$. flex. digiti quinti brevis reaches nearly the level of the metatarso-phalangeal articulation where it forms the tendon attaching to the proximal end of the lateral metatarso-phalangeal sesamoid. 


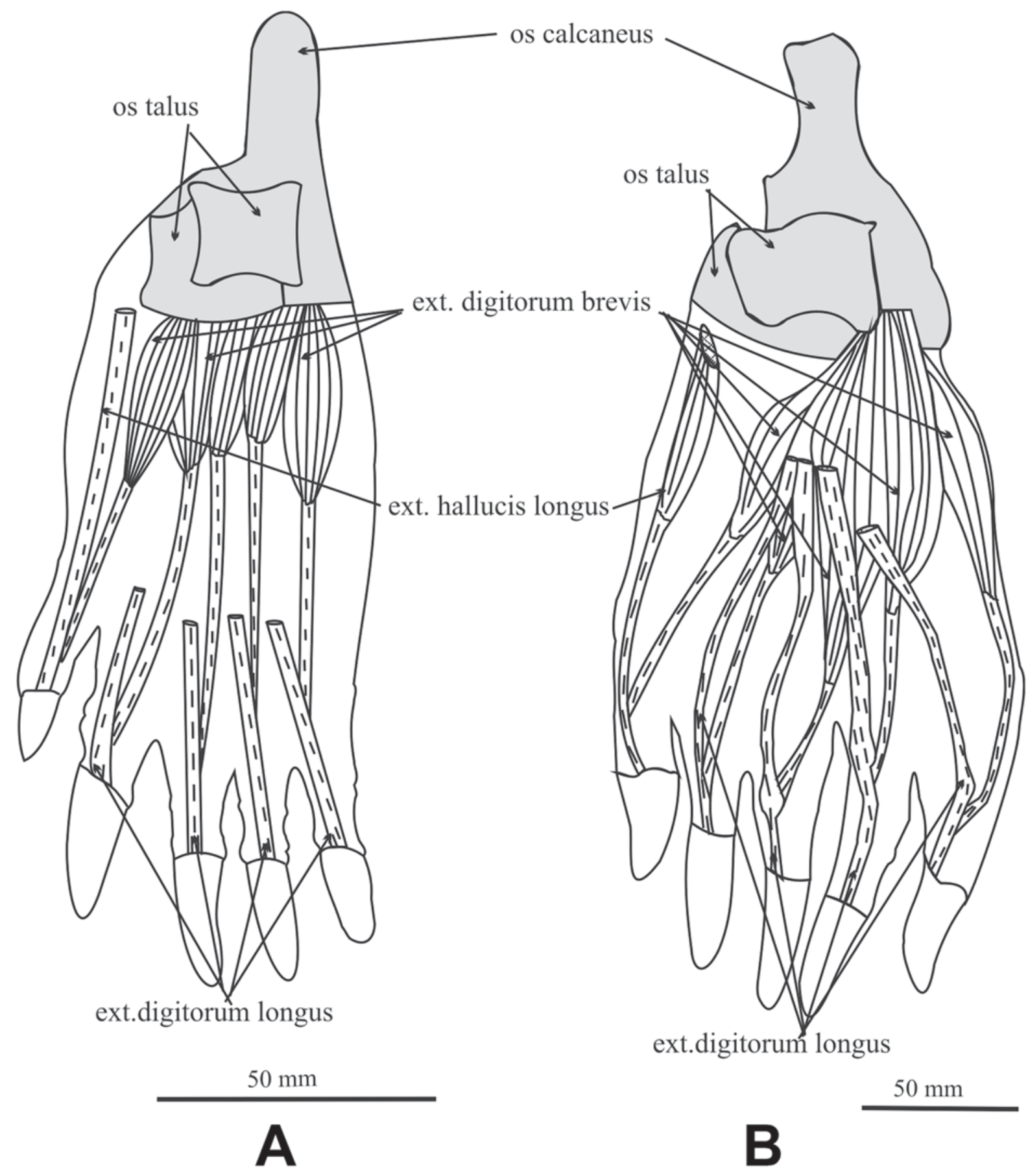

Figure 1. The muscles of the dorsal surface of the left pes.

A - Myrmecophaga tridactyla; B - Ursus arctos. Abbreviation: ext. - extensor.

2. M. abductor digiti quinti brevis in $M$. tridacty$l a$ is united with $\mathrm{m}$. flex. digitorum brevis so firmly that they look like a single muscle (Fig. 2). These muscles arise from both lateral and medial sides of the tuber calcanei, $\mathrm{m}$. flex. digitorum brevis being the superficial. However, there is a dense fibrous layer between the origin of $\mathrm{m}$. abd. digiti quinti brevis and $\mathrm{m}$. flex. digitorum brevis and, though fused, the muscles thus keep their independence. The venter of m. flex. digiti quinti brevis forms a tendon at the level of the proximal epiphysis of os metatarsi $\mathrm{V}$, which runs deeper than the terminal branch from the tendon of the $\mathrm{m}$. peroneus brevis and then lies in the groove formed in the thickness of $\mathrm{m}$. flex. digiti quinti brevis sensu stricto extend- 


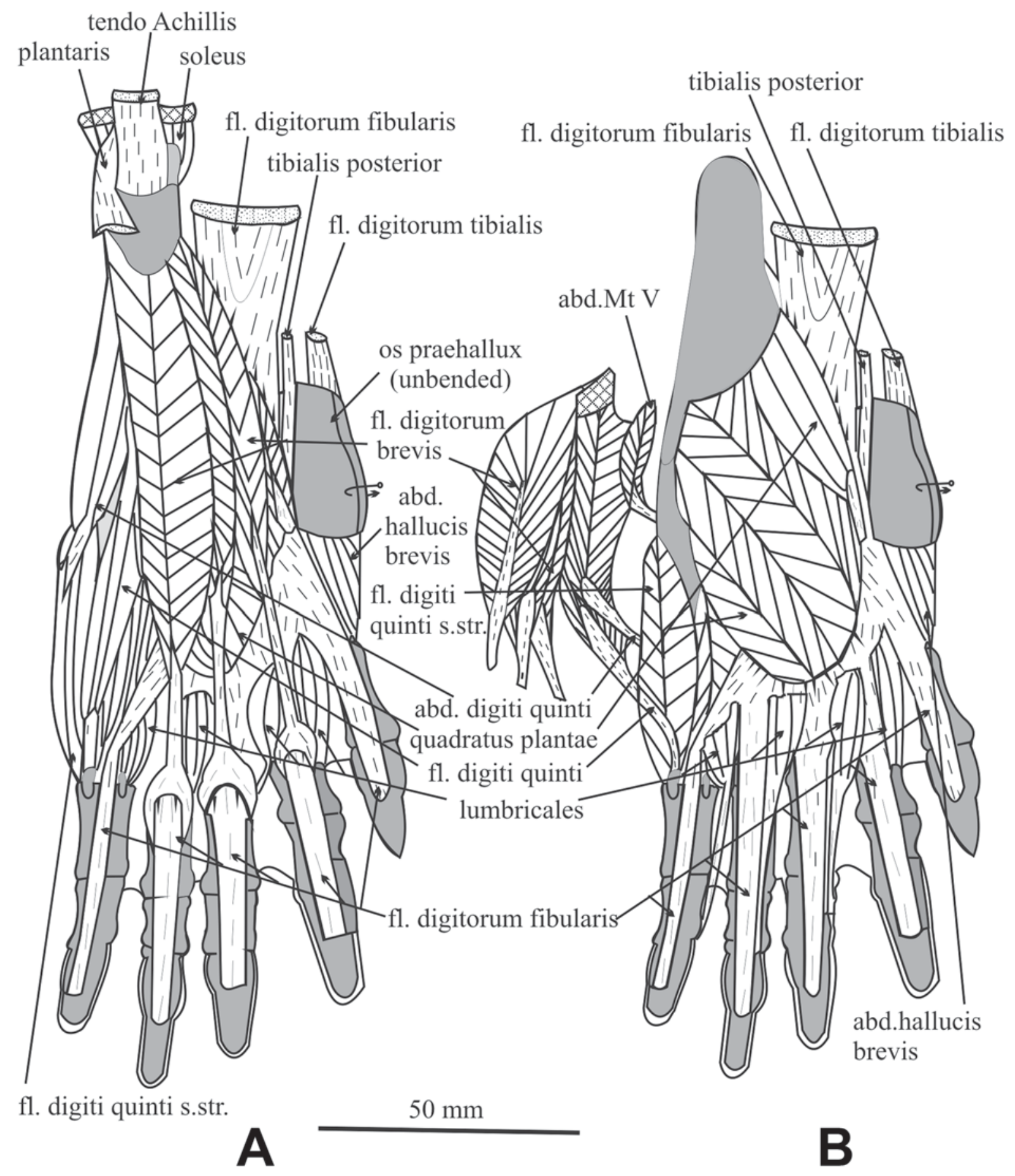

Figure 2. The superficial muscles of the plantar side of left pes in Myrmecophaga tridactyla.

A — first layer; B — second layer. Abbreviations: abd. — abductor; add. — adductor; fl. — flexor; s. str. — sensu stricto; Mt. V — metatarsalia V.

ing up to the proximal end of the lateral side of the first phalanx of fifth digit.

3. M. abductor metatarsi V. The muscle venter inculcates between venters of $\mathrm{m}$. abductor digiti quinti and $\mathrm{m}$. flex. digitorum brevis at the middle of the latter
(Fig. 2). M. abd. metatarsi V originates as an additional bundle of $\mathrm{m}$. flex. digitorum brevis separated from the whole muscle close to the distal end of the tuber calcanei where the bundle forms a tendon inserted into the proximal end of the latero-plantar surface of os metatarsi V. 


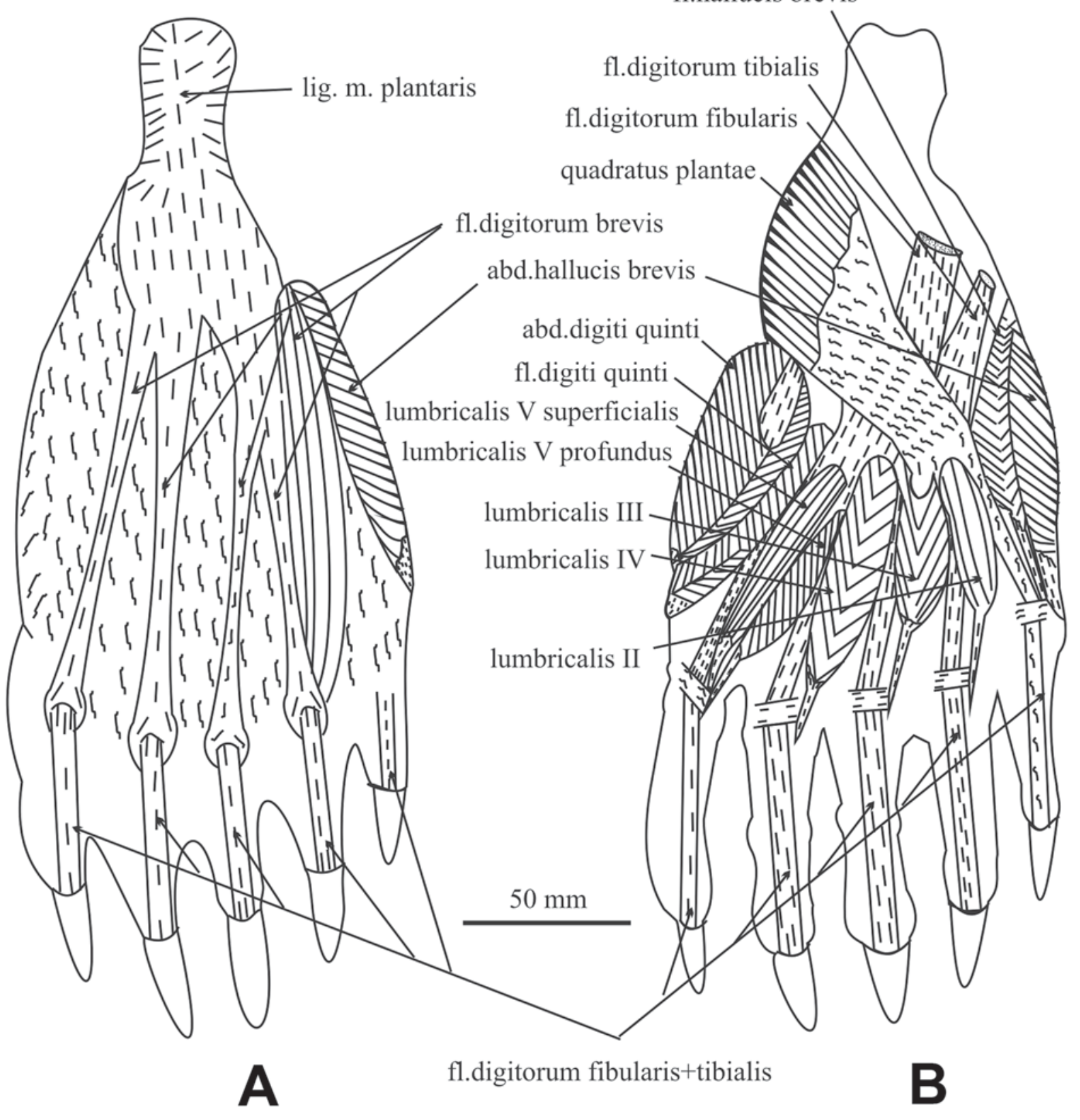

Figure 3. The superficial muscles of the plantar side of left pes in Ursus arctos.

A — first layer; B — second layer. Abbreviations: abd. — abductor; add. — adductor; fl. — flexor; lig. m. — ligamentum musculi.

In the brown bear there are only two muscles in this area:

1. M. abductor digiti quinti takes origin from the latero-distal margin of the sesamoid lying between cuboid (carpalia IV+V) and os metatarsi V, and also from the vertical tendinous plate from which the bundles of $\mathrm{m}$. flex. digiti quinti brevis arise (Figs 3B, 4A). The muscle inserts onto the latero-proximal edge of lateral metatarso-phalangeal sesamoid. The most lateral bundles convert into a tendon which fuses with the tendon of $\mathrm{m}$. ext. digitorum longus of the fifth digit.
2. M. flexor digiti quinti brevis arises from the plantaromedial surface of the tendinous plate and the sesamoid mentioned above, and is inserted into the proximal end of the medial metatarso-phalangeal sesamoid (Figs 3B, 4A).

M. quadratus plantae in $M$. tridactyla originates from the lateral tuberosity of the calcaneus more distal to the groove for the tendon of $\mathrm{m}$. flex. digitorum fibularis. The muscle attachment extends as far as the distal part of the calcaneus plantar surface. The area of the origin is from the level of proximal third to the distal 


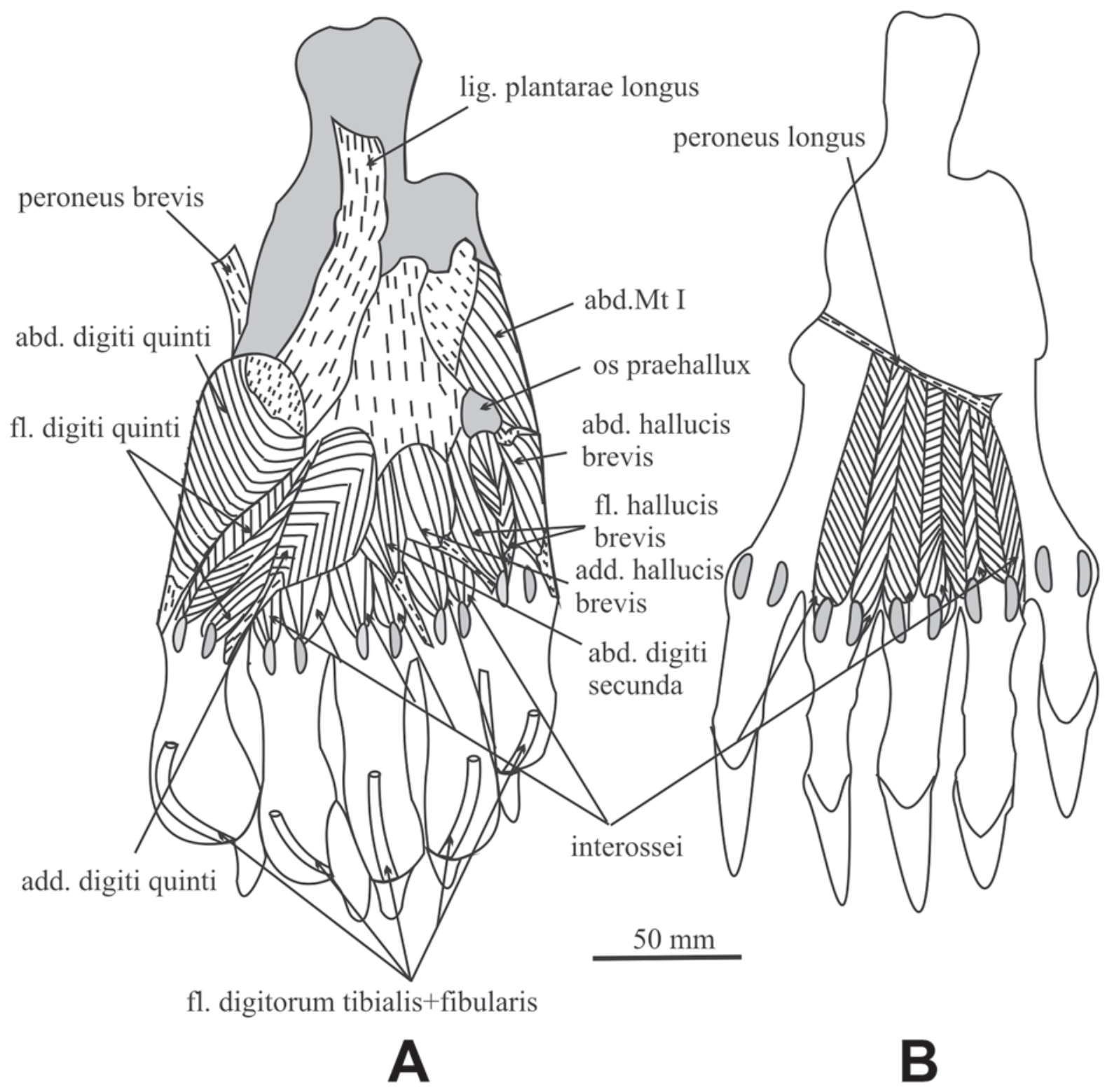

Figure 4. The deep muscles of the left pes in Ursus arctos.

A — third layer; B — fourth layer. Abbreviations: abd. — abductor; add. — adductor; fl. — flexor; lig. — ligamentum; Mt. I — metatarsalia I.

end of the calcaneus on the lateral side and is similar on the medial side but beginning from the middle of the bone length. Thus, the origin of muscle crosses the calcaneus obliquely (Fig. 2). The muscle inserts upon the plantar surface of the common tendinous plate of $\mathrm{m}$. flex. digitorum fibularis forming a special aponeurosis from the medial side responsible for the tension of the medial tendon of the flexor. The aponeurosis is inserted upon the surface of tendinous lamina. The area of origin extends up to its branching toward the third digit.

In the brown bear, m. quadratus plantae originates from the lateroplantar surface of the calcaneus and then passes to the same surface of the cuboid (Fig. 3B). The muscle ends by a flat tendon mainly on the medial side of the common tendinous plate which is the derivative of the tendons of $\mathrm{m}$. flex. tibialis et fibularis. The area of insertion extends to the branching of the plate toward the fifth digit.

Mm. lumbricales in the giant anteater are four small muscles which are placed among the tendons of m. flex. digitorum fibularis (Fig. 2). Then the muscles run to the medial sides of the second-fourth digits where they become lost in the fibrous mass at the level of the first phalanxes of the corresponding digits. However, the venter situated between the fourth and fifth tendons of $\mathrm{m}$. flex. digitorum fibularis is recognizable 
up to the plantaromedial surface of the ungual phalanx of the fifth digit.

In the brown bear, mm. lumbricales arise as four muscular venters fixed between the tendons of $\mathrm{mm}$. flex. digitorum fibularis et tibialis (Fig. 3A). One of them is double and sites between the tendons to the fourth and fifth digits; in so doing the superficial venter lies along the plantar surface of the tendon to the fifth digit and inserts on the plantaromedial side of the tendinous plate of the holed tendon of $\mathrm{m}$. flex. digitorum brevis. The second, deeper venter is between the tendons to the fourth and fifth digits, where it passes from the plantar to dorsal surface. This half-separated venter is inserted on the medial side of the holed tendon, and its bundles are hardly traceable as far as the medial surface of the distal end of the second phalanx of fifth digit.

The next venter of mm. lumbricales lies between the tendons of $\mathrm{mm}$. flex. digitorum fibularis et tibialis to the third and fourth digits. On the plantar surface it sides with the third venter disposed between the second and third digits and then it appears as a small part on the dorsal surface in the corner between above mentioned tendons. The terminal flat tendon is adjacent to the holed tendon of $\mathrm{m}$. flex. digitorum brevis and then runs along the medial surface up to the distal end of the second phalanx of the fourth digit. On the dorsal side the tendon sides to another tendon which gets over the dorsal side where it joins with the tendon of $\mathrm{m}$. ext. digitorum longus. Thus the second tendon of mm. lumbricales ends onto the medial surface of the distal end of the second phalanx of fourth digit while the tendon fused with the extensor tendons is an independent one which adjoins the terminal tendon of $\mathrm{mm}$. lumbricales.

The third venter is inserted on the medial side of the proximal end of the first phalanx of third digit. The fourth venter is attached to the medial surface of the metatarsophalangeal sesamoid of the second digit.

There are also several ligaments on the plantar side of the foot below the tendon of $\mathrm{m}$. flex. digitorum fibularis. One of them runs from the medial margin of the calcaneus distal end to the base of os praehallux. M. flex. hallucis brevis takes origin from this ligament and from the plantar surfaces of tarsalia I and os metatarsi I. Below the ligament, there is a transverse ligament from tarsalia I to tarsalia II-V directed whose distal end serves as the base for the following three muscles:

1. M. adductor digiti secunda brevis in the giant anteater arises from the middle third of the transverse ligament. The muscle ends on the lateral surface of the proximal end of the first phalanx of second digit (Fig. 5A).

In the brown bear, this muscle arises from the ligaments which cover the groove for $\mathrm{m}$. peroneus longus and extends for about one tenth of the pes width being also fixed on the medial edge of $\mathrm{m}$. adductor digiti quinti brevis (Fig. 4A). The muscle insertion is the same as in the giant anteater.

2. M. adductor digiti quinti brevis in the giant anteater originates more laterally from the same liga- ment and extends for approximately one sixth of its length (Fig. 5A). The muscle is inserted upon the medial surface of the proximal end of the first phalanx of 5th digit.

In the brown bear, the muscle arises from the plantar tendinous plate located at the level of the tarsals, where it occupies from a quarter to a half of the pes width, and from the intermediate tendinous plate between the muscle and $\mathrm{m}$. adductor digiti II (Fig. 4A). The insertion of $\mathrm{m}$. adductor digiti quinti brevis is on the proximal end of the medial surface of the first phalanx of fifth digit.

3. M. adductor hallucis brevis in the giant anteater takes origin from the medial side of the transverse ligament from its distal margin (Fig. 5A). The insertion is upon the lateral surface of the proximal end of the first phalanx of the first digit.

In the brown bear, the $\mathrm{m}$. adductor hallucis brevis originates from the distal margin of the ligaments that cover the groove for the terminal tendon of $\mathrm{m}$. peroneus longus (Fig. 4A). In this case the adductor extends laterally from the level of praehallux for about one third of the pes width. The muscle also takes origin from the medial margin of $m$. adductor digiti secunda and from the vertical tendinous plate fixed on the latero-distal margin of the praehallux and on the lateral labium of os metatarsi I. The insertion is the same as in the giant anteater.

M. abductor hallucis brevis in $M$. tridactyla arises from the distal margin of the praehallux and inserts on the medial surface of the proximal end of the first phalanx of the first digit (Figs 2, 5A).

In the brown bear, it takes origin from the plantaromedial surface of praehallux and from the medial labium of os metatarsi I (Figs 3B, 4A). The insertion is the same as in the giant anteater.

M. abductor metatarsi I is found in $U$. arctos only. It arises via a tendon from the mediodistal edge of the plantar surface of the calcaneus and from the plantar surface of the tendinous plate fixed between the calcaneus and tarsalia I (Fig. 4A). The muscle runs deeper the praehallux up to the medioproximal end and the plantar surface of the medial condyle of os metatarsi I. On the way the muscular venter is also attached by its plantar fascia on the internal (dorsal) surface of the praehallux.

M. flex. hallucis brevis in M. tridactyla originates from the transverse ligament that passes from the medial margin of the calcaneus distal end to the base of praehallux and from the lateral surface of the base of praehallux (Fig. 5A). The insertion is on the medial side of the metatarsophalangeal sesamoid of first digit.

In the brown bear, the muscle arises from the plantarolateral surface of praehallux and is inserted into the proximal end of the medial metatarsophalangeal sesamoid of first digit (Fig. 4A).

The three latter muscles fully replace $\mathrm{m}$. interossei of the first digit.

Mm. interossei in M. tridactyla consist actually of eight muscles, which are arranged in pairs on the four 


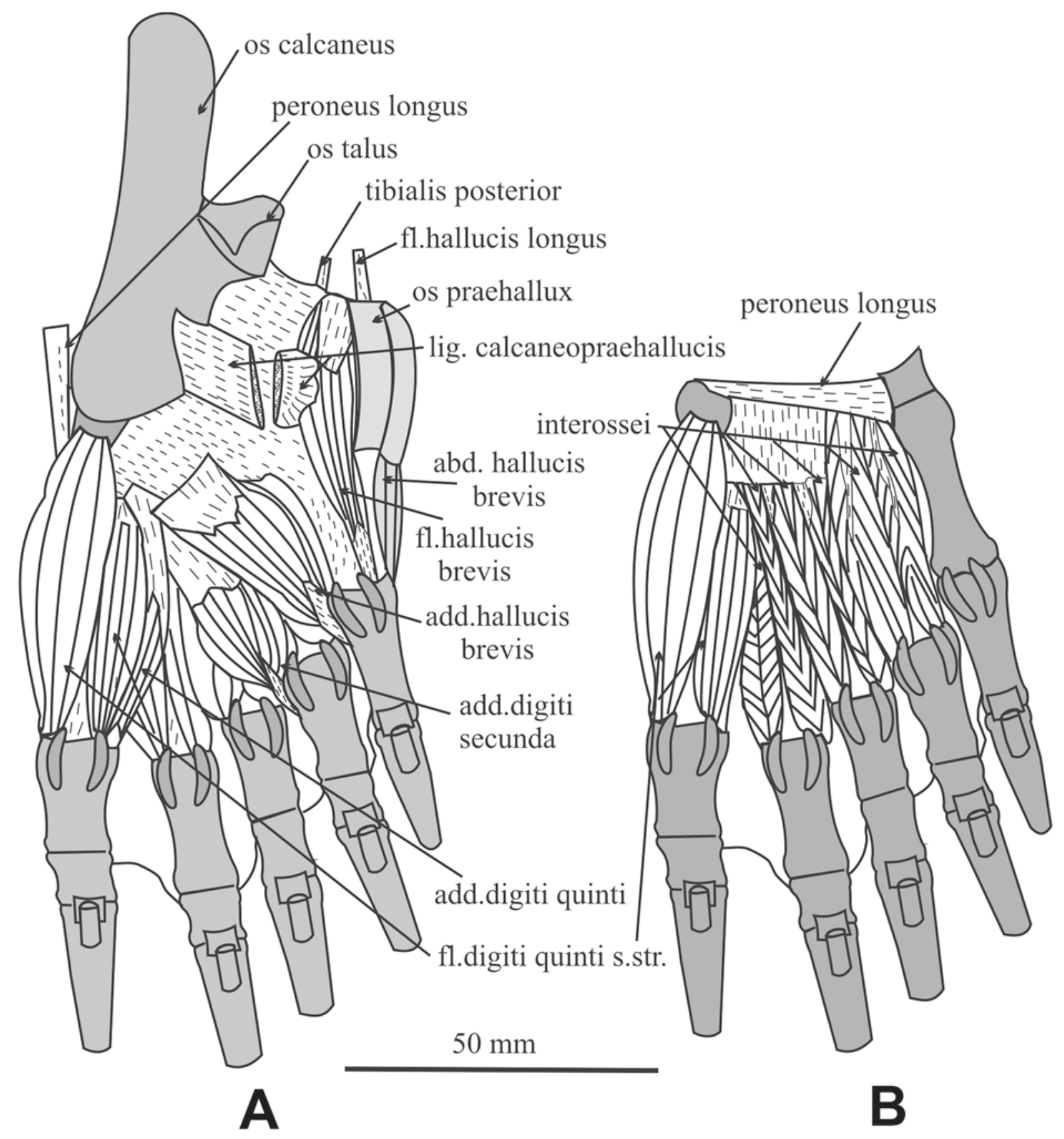

Figure 5. The deep muscles of the left pes in Myrmecophaga tridactyla.

A — third layer; B — fourth layer. Abbreviations: abd. — abductor; add. — adductor; ext. — extensor; fl. — flexor; lig. — ligamentum; Mt. III - metatarsalia III.

lateral digits (Fig. 5B). All muscles originate from the fibrous cover of the tendon of $\mathrm{m}$. peroneus longus. The tendon extends from the eminence of tarsalia V+IV that covers the canal for $\mathrm{m}$. peroneus longus on the plantar side and runs above the metatarsal bones and ends upon tarsalia I and os metatarsi I. These fibrous ligaments serve for strengthening the pes and also make the base for the insertion of all $\mathrm{mm}$. interossei. Furthermore, each muscle is inserted into the lateral and medial labia of the metatarsals. Two most lateral muscles called m. flex. digiti quinti sensu stricto originate from the plantar surface of tarsalia V+IV and insert into the corresponding sesamoids (Fig. 5). According to the human body anatomy, $\mathrm{m}$. interossei medialis digiti $\mathrm{V}$ would be called the medial head of $\mathrm{m}$. flex. digiti quinti brevis. However, they can be called the medial and lateral heads of $\mathrm{mm}$. interossei plantaris because there is no single muscle of $\mathrm{mm}$. interossei in the dorsal side of the pes. 


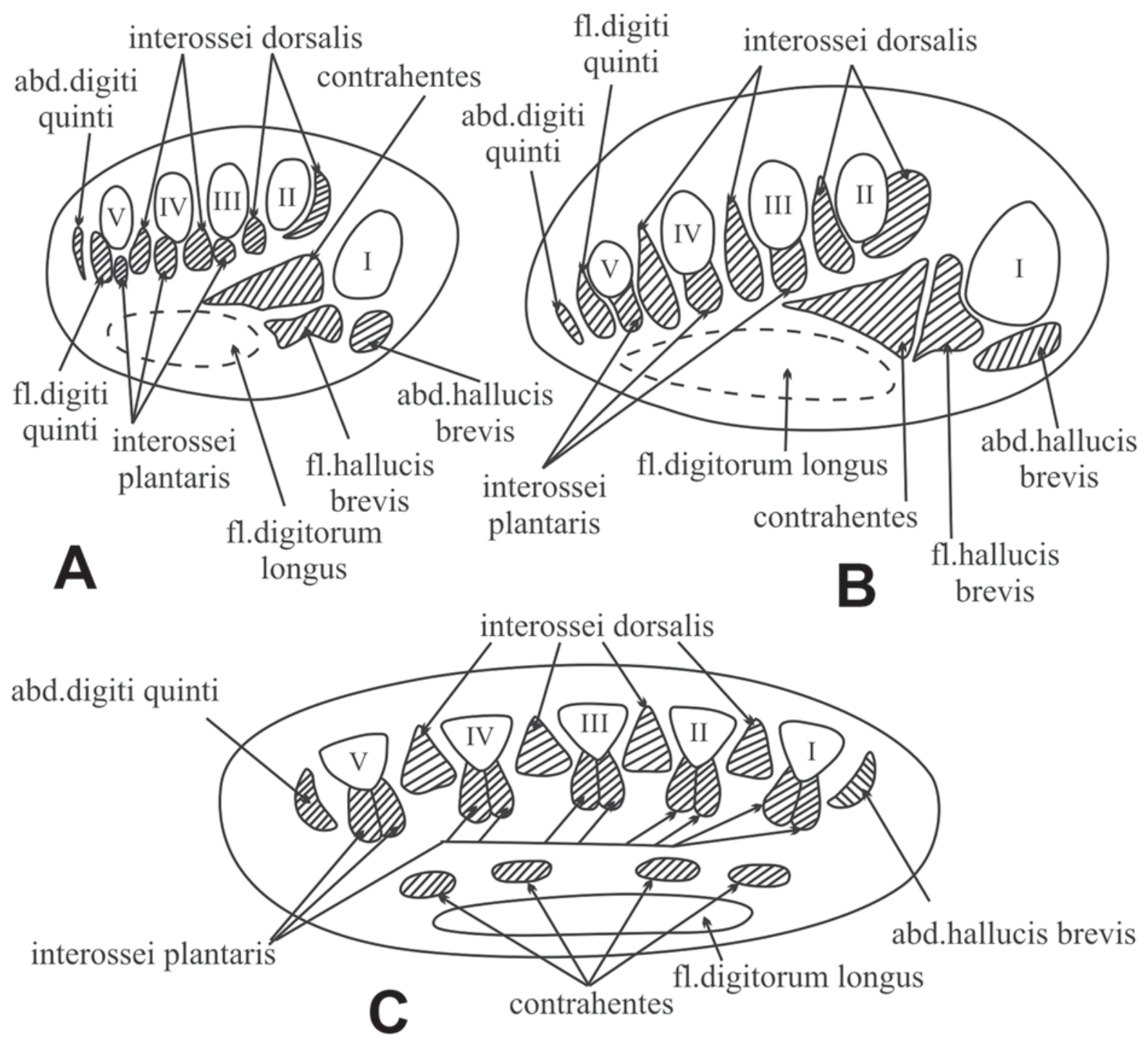

Figure 6. The diagram showing the origin ways of the $\mathrm{mm}$. interossei dorsalis in mammals. A, B - in Ruge, 1878; C — in Cunningham, 1879. Abbreviations: abd. — abductor; fl. — flexor.

In the brown bear, mm. interossei are six muscles, each arising by two heads from three middle digits (Fig. 4). They originate both from the ligaments and from the plantar surface of the matatarsals (on each ray and from each other).

It is considered that a man have only two types of $\mathrm{mm}$. interossei of the pes, namely, mm. interossei plantaris and $\mathrm{mm}$. interossei dorsalis: lateral and medial $\mathrm{mm}$. interossei dorsalis passing to the second digit, $\mathrm{m}$. interossei dorsalis located only on the lateral sides of the third and fourth digits, and $\mathrm{m}$. interossei plantaris arising from the lateral side of the third and fourth digits and from the medial side of the fifth digit (Sinelnikov, 1952). Mm. interossei in primates are observed both in the hand (dorsal and volar muscles) and in the pes (dorsal and plantar muscles). In M. tridactyla there are four $\mathrm{mm}$. interossei in the hand and none in the pes. We suppose that schema of the origin of $\mathrm{mm}$. interossei plantaris, dorsalis seu volaris (Cunningham, 1879, 1881; Fitzwilliams, 1910; Jouffroy, 1962; Jouffroy et al., 1971 ) in the hand and foot are not in agreement with the way of origin of the $\mathrm{m}$. interossei dorsalis. This is well demonstrated by the example of origin of the $\mathrm{mm}$. interossei dorsalis in human embrio (Ruge, 1878), where these muscles are the simple dorsal projections of the lateral heads of $\mathrm{mm}$. interossei plantaris on the three middle digits of the pes (Fig. 6).

In the brown bear, only a small part of lateral $\mathrm{m}$. interossei of the second digit appears on the dorsal surface of the metatarsal while the others are situated only on the plantar surface (Fig. 4). Therefore, there is ample evidence that its three middle digits have two $\mathrm{mm}$. interossei plantaris, and further analogously that its $\mathrm{mm}$. abductor hallucis brevis and flex. digiti quinti 


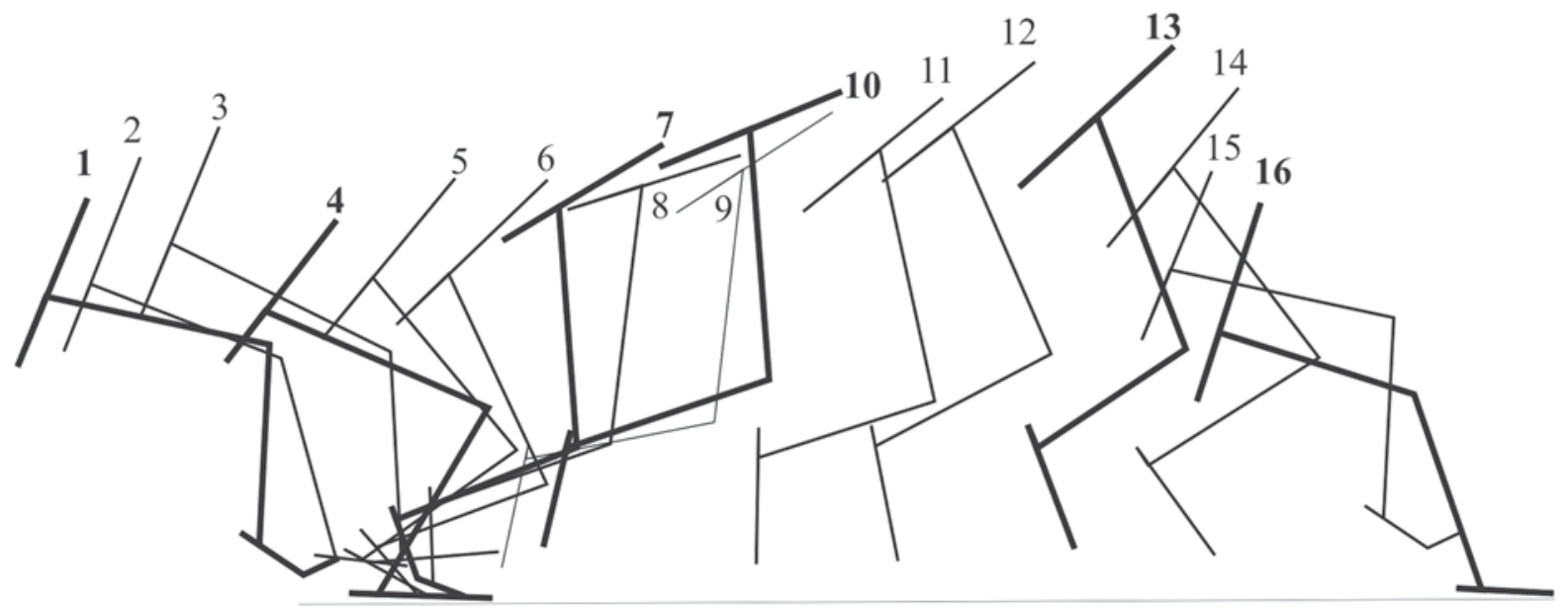

Figure 7. The transference of the hindlimb bones in run cycle of plantigrade mammals. 1-2, 9-15 - transfer phases; 3-8, 16 - foothold phases.

brevis are homologous to medial mm. interossi, and $\mathrm{mm}$. abductor digiti quinti brevis and flex. hallucis brevis are homologous to lateral $\mathrm{mm}$. interossei. Both $\mathrm{mm}$. interossei of the second digit are inserted into the proximal end of the metatarsophalangeal joint and pass further to join the extensor tendon of the second digit on both sides; mm. interossei of the third and fourth digits have the same insertion.

\section{The action of the pes muscles}

During the terrestrial locomotion in the giant anteater, both the short and long muscles participate in the pes work.

Above we have described only the short muscles, but the functional features of the pes are discussed with reference to data on all muscles that end on the foot. The giant anteater is able to gallop (Shaw et al., 1985, 1987). Thus, we begin the discussion with the action of pes muscles in gallop, the fastest allure which may imprint on the anatomy of locomotor organs (Gambaryan, 1974). The pes work in gallop occurs in two unequal phases: transfer (Fig. 7: 1-2, 9-15) and foothold (Fig. 7: 3-8, 16). At the beginning of the transfer phase, after the foot has lost a contact with the ground, the crus-to-pes angle is maximum. In human anatomy, the ankle-joint flexion corresponds to what is called the ankle-joint extension in monograph "How mammals run" of Gambaryan (1974). Therefore, we use here the crus-to-pes angle rather than the ankle-joint flexion or extension to avoid terminological confusion. This angle decreases in the first half of the transfer phase (Fig. 7: 9-15) and then increases slightly in its second half till the moment of pes contact with the ground when the angle reaches the maximum for transfer phase.

The muscles responsible for decreasing the crus-topes angle at the beginning of transfer phase are $\mathrm{m}$. peroneus brevis that ends at the lateral edge of the pes, $\mathrm{m}$. ext. hallucis longus, inserting together with the me- dial tendon of $\mathrm{m}$. ext. digitorum brevis, into the ungual phalanx of the first digit, and also m. ext. digitorum longus and $\mathrm{m}$. tibialis anterior, which attach between preceding two muscles on the pes. M. tibialis anterior is especially well developed (Tab. 1) and ends in the middle of the proximal pes end, which is the most convenient to change the angle.

At the end of transfer phase the action of muscles responsible for propulsion starts that is resulted anew in increasing of the crus-pes angle. The angle increases by contraction of all heads of mm. gastrocnemius and plantaris inserted upon the apex of the tuber calcanei, and also of $\mathrm{m}$. flex. diginorum fibularis inserted into all ungual phalanxes. Having provided the propulsive push, the muscles proceed also their action at the foothold phase which begins right after the heel touches the ground. However, although the muscles which increase the crus-pes angle continue their action and the pes lies on the ground that would likewise increase this angle, the transfer of the body above the support rather causes the angle decrease (Fig. 7). It keeps decreasing until the heel detaches from the ground and then begins to enhance again to reach the maximum by the end of support phase.

At the foothold phase, the ground roughness induces the action of the short muscles. Besides the muscles inserted into the pes, propulsive push is also provided by the more proximal muscular complexes of other hindlimb joints but their work is beyond our consideration.

Two heads of mm. gastrocnemius, soleus and plantaris are inserted into the apex of the tuber calcanei. These muscles, together with m. flex. digitorum fibularis, are responsible for the support of the pes into the ground. In the giant anteater, m. soleus arises from the fibula and is better developed than the other muscles (Tab. 1). The great development and topography of this muscle are similar with such in the brown bear. Both anteaters and brown bears can gallop and both have well developed short pes muscles. 
Table 1. The muscles acting upon the pes. A - muscles; B - absolute weight (g); C - percent of total weight of hindlimb muscles; D — weight of forelimbs muscles respective to total weight of hindlimbs and forelimbs muscles (\%); $\mathrm{E}$ and $\mathrm{G}$ - percent of total weight of all muscles that act upon the pes in Myrmecophaga tridactyla (E) and Ursus arctos (G).

\begin{tabular}{|c|c|c|c|c|c|}
\hline A & B & $\mathrm{C}$ & $\mathrm{D}$ & $\mathrm{E}$ & $\mathrm{G}$ \\
\hline gastrocnemius lateralis & 15.5 & 1.13 & 0.42 & 7.54 & 4.61 \\
\hline gastrocnemius medialis & 29.7 & 1.97 & 0.72 & 13.06 & 6.53 \\
\hline plantaris & 9.5 & 0.65 & 0.24 & 4.34 & 21.19 \\
\hline soleus & 30.3 & 2.08 & 0.77 & 13.84 & 12.17 \\
\hline tibialis anterior & 23.4 & 1.64 & 0.60 & 10.64 & 7.71 \\
\hline ext. digitorum longus & 13.8 & 0.95 & 0.35 & 6.30 & 7.98 \\
\hline ext. hallucis longus & 1.3 & 0.09 & 0.03 & 0.63 & 1.12 \\
\hline peroneus longus & 11.1 & 0.76 & 0.28 & 5.07 & 3.02 \\
\hline peroneus brevis & 17.5 & 1.20 & 0.44 & 7.99 & 2.98 \\
\hline peroneus digiti quinti & 0 & 0 & 0 & 0 & 1.05 \\
\hline tibialis posterior & 10.7 & 0.74 & 0.27 & 4.89 & 4.71 \\
\hline fl. digitorum tibialis & 6.5 & 0.45 & 0.16 & 2.97 & 2.44 \\
\hline fl. digitorum fibularis & 22.7 & 1.56 & 0.57 & 10.37 & 14.85 \\
\hline fl. digitorum brevis & 8.7 & 0.60 & 0.22 & 3.97 & 0.40 \\
\hline quadratus plantae & 3.8 & 0.26 & 0.10 & 1.74 & 0.99 \\
\hline abd. digiti quinti & 2.4 & 0.16 & 0.06 & 1.10 & 1.73 \\
\hline lumbricalis $\mathrm{V}$ & 0.2 & 0.01 & 0.01 & 0.09 & 0.30 \\
\hline lumbricalis IV & 0.16 & 0.01 & 0.00 & 0.07 & 0.18 \\
\hline lumbricalis III & 0.1 & 0.01 & 0.00 & 0.05 & 0.11 \\
\hline lumbricalis II & 0.06 & 0.00 & 0.00 & 0.03 & 0.06 \\
\hline interossei lateralis V & 1.98 & 0.14 & 0.05 & 0.90 & 0.00 \\
\hline interossei lateralis IV & 0.88 & 0.06 & 0.02 & 0.40 & 0.67 \\
\hline interossei lateralis III & 0.58 & 0.04 & 0.01 & 0.26 & 0.36 \\
\hline interossei lateralis II & 0.3 & 0.02 & 0.01 & 0.14 & 0.46 \\
\hline interossei medialis $\mathrm{V}$ & 0.3 & 0.02 & 0.01 & 0.14 & 0.66 \\
\hline interossei medialis IV & 0.32 & 0.02 & 0.01 & 0.15 & 0.27 \\
\hline interossei medialis III & 0.08 & 0.01 & 0.00 & 0.04 & 0.28 \\
\hline interossei medialis II & 0.32 & 0.02 & 0.01 & 0.15 & 0.38 \\
\hline abd. hallucis & 0.62 & 0.04 & 0.02 & 0.28 & 0.92 \\
\hline add. brevis I & 0.22 & 0.02 & 0.01 & 0.10 & 0.20 \\
\hline add. brevis II & 0.32 & 0.02 & 0.01 & 0.15 & 0.06 \\
\hline ext. digitorum brevis & 4.63 & 0.25 & 0.11 & 2.12 & 1.63 \\
\hline muscles of the pes & 218.97 & 15.05 & 5.51 & 100.00 & 100.00 \\
\hline posterior extremities & 1454.87 & 100.00 & 36.80 & & \\
\hline anterior extremities & 2498.38 & 171.73 & 63.20 & & \\
\hline posterior + anterior extremities & 3953.25 & 271.73 & 100.00 & & \\
\hline
\end{tabular}

The short muscles of the pes act separately or assist the long pes muscles in their work. The m. flex. digitorum brevis, ending on the metatarsophalangeal sesamoids, has quite an independent influence on the pes by increasing the tension in the metatarsophalangeal region. This increases the support force of the pes upon the ground that is undoubtedly favorable for locomo- tion. The mm. interossei carry out the same function. The $\mathrm{m}$. adductor hallucis acts together with $\mathrm{m}$. peroneus longus to increase the pressure of the pes on its medial side (Figs 4, 5). The mm. abductor halucis and abductor digiti quinti widen the pes by abducting the extreme digits, and thus adapting the pes to the rough ground. The joint action of different short muscles, each being 
charged with a specific small function, provides successful work of the pes in the run on the rough surface of the soil.

The action of the mm. ext. digitorum longus and flex. digitorum fibularis on the opposite sides of the pes is worth attention being considered in more detail as their tension increase is critical for the locomotion.

M. ext. digitorum longus acts in the beginning of the transfer phase and facilitates the transfer of the pes in grasslands by raising the toes off the ground. The $\mathrm{m}$. flex. digitorum fibularis ends on the ungual phalanxes of all five digits and its action improves the cohesion of the pes with the ground at the support phase. The terminal tendons of the $\mathrm{m}$. ext. digitorum longus and the $\mathrm{m}$. flex. digitorum fibularis serve also for the insertion of such auxiliary muscles as the m. ext. digitorum brevis and the m. qudratus plantae, respectively. The importance of auxiliary muscles for locomotion and their functions have been elucidated earlier (Gambaryan, 1957).

Thus, in the common mole Talpa europaea, the brachial heads of the $\mathrm{m}$. flex. digitorum profundus converts into the tendon that arises from the medial epicondyle of the humerus and ends on the ungual phalanxes of all five digits. Weak muscular fibers of the radial and ulnar heads of the flexor insert upon the middle part of its tendon. Although being apparently weak, the muscular heads are essential agents in the mole locomotion.

The point is that the forelimbs are subject to great tension when the mole is digging the soil apart. This tension is withstood by weak action of the radial and ulnar heads of the $\mathrm{m}$. flex. digitorum profundus which have no need of being strong because the greater the tension of the main tendon, the greater the total strength of these heads (Gambaryan, 1957).

The short pes muscles in the giant anteater act by the same mechanism: the tendons of the m. quadratus plantae are inserted upon the tendons of the m. fex. digitorum fibularis that increases the tension force of the latter (Fig. 8B); the same is the effect of the m. ext. digitorum brevis on the $\mathrm{m}$. ext. digitorum longus (Fig. 8A). The stronger the pull of the tendons of the m. flex. digitorum fibularis, the greater the effect of the $\mathrm{m}$. quadratus plantae in strengthening the latter (Fig. 6).

Thus, the pull of the two short muscles in the anteater straightens the tendons of the m. ext. digitorum longus and the $\mathrm{m}$. flex. digitorum fibularis in the same way as the pull of the radial and ulnar heads upon the tendon of the m. flex. digitorum profundus in the mole. It is worthy of note that the auxiliary muscles in the anteater have lower relative weights than the main muscles (Tab. 1): the weight ratio is about 3:1 for m. ext. digitorum longus and $\mathrm{m}$. ext. digitorum brevis and still greater $-6: 1$ for the $\mathrm{mm}$. flex. digitorum fibularis and quadratus plantae.

In moles (Talpidae), the weight of the m. flex. digitorum profundus correlates with both the mechanism of muscle action and the degree of burrowing specialization. Thus, in highly specialized Mogera the weight ratio of tendon of the $\mathrm{m}$. flex. digitorum profundus to auxiliary heads is nearly 7:1 and in less specialized Neurotrichus - 5:1 (unpublished data).

In the anteater, the terminal tendons of the mm. flex. digitorum fibularis and ext. digitorum longus only after their bending to the pes convert into the tendons where the auxiliary muscles are inserted and, thus can affect on the main muscles. The $\mathrm{m}$. flex. digitorum fibularis plays more important role in the anteater locomotion than $\mathrm{m}$. ext. digitorum longus and so has the greater weight relative to the auxiliary muscles.

\section{Discussion}

Giant anteaters are highly specialized animals feeding solely on termites (Shaw et al., 1985; Naples, 1999). Their forelimbs are perfectly adapted to opening the tight walls of termite nests that requires some specialization in burrowing (Young et al., 2003). To clarify the degree of this burrowing specialization and the imprint of adaptation to running on the pes anatomy of giant anteater, we analyzed the weight ratios of the forelimb-to-hindlimb muscles (Tab. 2). The weight of the forelimb muscles is almost twice that of hindlimb muscles. This weight proportion is evidence of a high specialization in burrowing and also indicates that adaptation to running is secondary. For better illustration of the correlation between the degree of specialization in burrowing and the weight ratio of the forelimbs to hindlimbs muscles, we compared the giant anteater with the armadillo as a representative of the same order Pilosa and with a number of specialized burrowers from other orders (Tab. 2).

All armadillos are anyhow adapted to the burrowing. However, most of species feed by burrowing activity as well as by searching carrion and fruits and therefore need to develop running more than burrowing.

Table 2. Weight ratio of forelimb and hindlimb muscles (\%). A - species; B — forelimb/hindlimb muscles weight ratio.

\begin{tabular}{|l|c|}
\hline \multicolumn{1}{|c|}{ A } & B \\
\hline Myrmecophaga tridactyla & 1.7 \\
\hline Dasypus novencinctus & 0.4 \\
\hline Chaetotragus villosus & 0.8 \\
\hline Chlamyphorus truncatus & 2.4 \\
\hline Eremitalpa grantii & 4.4 \\
\hline Chrysochloris aureus & 4.5 \\
\hline Talpa europaea & 4.3 \\
\hline Mogera robusta & 4.5 \\
\hline Neurothrychus gibsii & 1.8 \\
\hline Spalax giganteus & 3.3 \\
\hline Nanospalax nerhingi & 3.2 \\
\hline Myospalax myospalax & 3.0 \\
\hline Prometheomys schaposhnikovi & 1.9 \\
\hline Ellobius lutescens & 2.4 \\
\hline Ellobius talpinus & 2.2 \\
\hline Rattus norvegicus & 0.6 \\
\hline
\end{tabular}




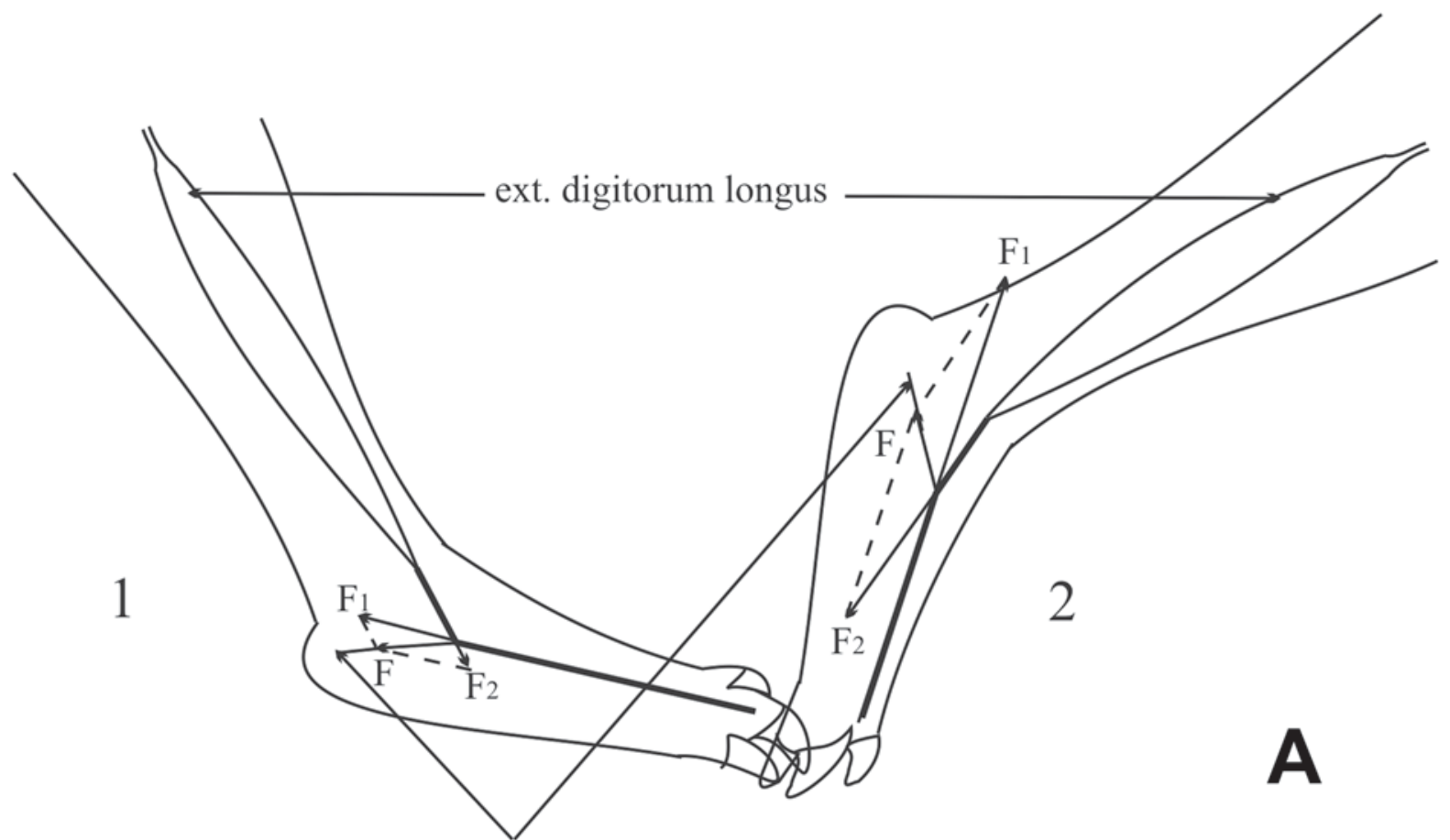

ext. digitorum brevis

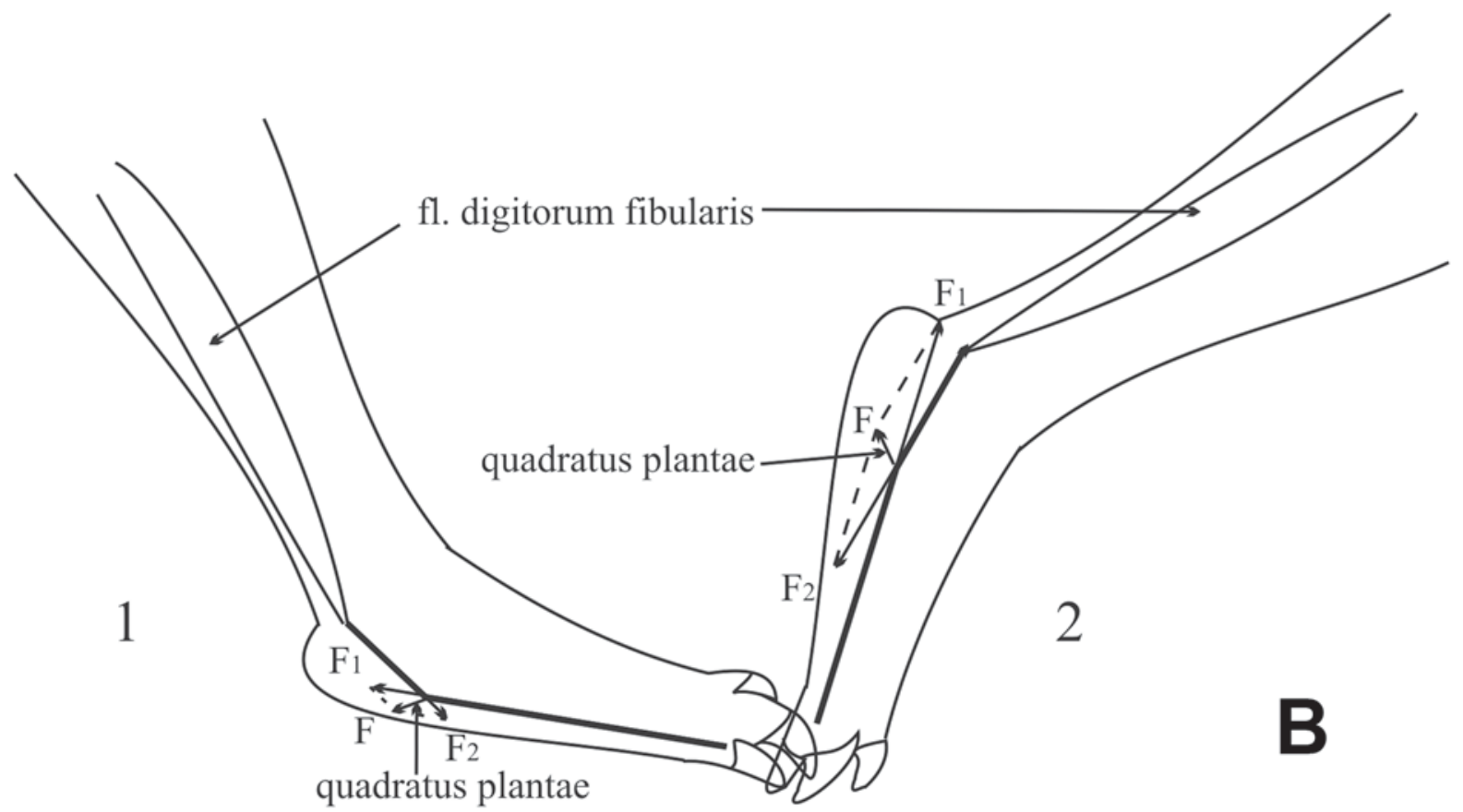

Figure 8. The diagram showing:

A - the influence of the $\mathrm{m}$. ext. digitorum brevis pull upon the tendons of $\mathrm{m}$. ext. digitorum longus: 1 - when the tendon of m. ext. digitorum longus is relaxed; 2 - when the tendon of $\mathrm{m}$. ext. digitorum longus is strained; $\mathrm{B}$ - the influence of the $\mathrm{m}$. quadratus plantae pull upon the tendons of $\mathrm{m}$. fl. digitorum fibularis: 1 - when the tendon of $\mathrm{m}$. fl. digitorum fibularis is relaxed; 2 - when the latter is strained. It is evident that the pull force of auxiliary muscles (F1, F2) increases when the respective main tendons straighten. Abbreviations: ext. extensor; fl. - flexor. 
High extent of specialization in burrowing among the armadillos is restricted to Chlamyphorus truncatus. This is a fossorial species which burrows fodder tunnels. Process of digging fodder tunnels is a hard work taking much energy and naturally influences on the locomotor organs anatomy. In Chlamyphorus truncatus, the muscles weight of forelimbs exceeds considerably such of the hindlimbs.

The specialized burrowers from other orders of mammals show similar tendency. Thus, in insectivorous and rodents, which as well as Chlamyphorus burrows fodder tunnels the ratio of muscles weight of the fore- to hindlimbs is in favor of the first of them, increasing in highly specialized burrowers (Tab. 2). For instance, this ratio is greater in highly specialized moles, such as Talpa, Mogera, and Scalopus, than in less specialized Urothrichus and Neurotrichus. Among rodents, in Spalax and Myospalax, highly specialized burrowers the ratio of muscles weight of the fore-and hindlimbs is also higher than in less specialized Ellobius and Prometheomys.

Although the anteater is a specialized burrower, terrestrial locomotion plays a greater role in its life than in other specialized fossorial burrowers. It roams over the open areas of prairies in South America looking for food and, besides, it can gallop when escaping from the predators (Shaw et al., 1985, 1987). This ability apparently has controlled an adaptive change of its pes. The reason is that its hindlimb muscles work in the same way but with lesser effort in other types of locomotion, and the locomotor organs are known to adapt to the maximum effort if the smaller effort is provided by the same action (Gambaryan, 1974). The reported comparison of pes myology of the giant anteater with that of the brown bear and some other plantigrade mammals showed many features of similarity. Therefore, the fact that the living giant anteater has a complete set of short pes muscles should be rather interpreted as adaptation to the running locomotion.

\section{Conclusions}

The giant anteater $M$. tridactyla is a highly specialized burrower which usually moves over the open areas of prairies in search of food and can gallop when escaping from the predators. We supposed that these locomotor properties in the giant anteater are correlated with the adaptive change of the pes and compared its pes mycology to that of the brown bear.

The work of the pes in gallop includes two phases: transfer and foothold. The latter is more loaded, and the power of the involved muscles is naturally much greater than that of the muscles acting in transfer phase. Correspondingly, the weight of the muscles that act in support phase $(\mathrm{mm}$. gastrocnemius lateralis et medialis, soleus, plantaris, flex. digitorum fibularis et tibialis and all of the short muscles on the plantar pes surface) is greater than the weight of those acting in transfer phase (mm. ext. digitorum longus et brevis, ext. hallucis lon- gus, tibialis anterior, peroneus brevis and peroneus digiti quinti). This distinction in muscles ratio is especially large in brown bear. Thus, the weight ratio of the muscles involved in the phase of foothold relative to those acting in transfer is about 3.3 in the brown bear and about 2.4 in the anteater (Tab. 1). The difference reflects various abilities to running of these two animals: the ratio is greater in the brown bear, which runs faster than the anteater.

Thus, the comparative analysis has shown that in spite of some differences above mentioned the work of the muscles acting on the pes in the giant anteater and brown bear is mainly similar, and this is consistent with the general similarity of the anatomy of these muscles. The similarity suggests also that the pes myology in the giant anteater bears imprint of adaptation to the run.

ACKNOWLEDGEMENTS. The study was supported by the Russian Fund of Fundamental Investigations (RFFI, grant \# 07-04-00706-a).

\section{References}

Cunningham D.J. 1879. The intrinsic muscles of the mammalian foot // Journal of Anatomy and Physiology, London. Vol.13. P.1-16.

Cunningham D.J. 1881. The nerves of the hind-limb of the Thylacine and the Cuscus // Journal of Anatomy and Physiology, London. Vol.15. P.265-277.

Cuvier G. 1849. Anatomie comparee recueil de planches de myologie. Paris. 235 pp.

Eisenberg J.F. \& Redford K.H. 1999. Mammals of the Neotropics: The Central Neotropics. Vol. 3. Chicago \& London: The University of Chicago Press. 609 pp.

Fitzwilliams D.C.L. 1910. The short muscles of the handoff the agile gibbon (Hylobates agilis) // Proceedings of the Royal Society, Edinburg. Vol.30. P.202-218.

Gambaryan P.P. 1957. [To the issue of feathered muscles] // Doklady Akademii Nauk Armyanskoi SSR. Vol.25. No.2. P.87-91 [in Russian with English summary].

Gambaryan P.P. 1974. How Mammals Run. New York: John Wiley. 334 pp.

Gardner A. 2005. Order Pilosa // D.E. Wilson, D.M. Reeder (eds.). Mammal Species of the World. A Taxonomic and Geographic Reference (Third edition). Baltimore: John Hopkins University Press. Vol.1. P.100-103.

Hildebrand M. 1988. Analysis of Vertebrate Structure. New York: John Wiley. 701 pp.

Jouffroy F.-K. 1962. La musculature des membres chez les lémuriens de Madagascar, etude descriptive et comparative. Thèses présentées a la faculte des sciences de l'université de Paris pour obtenir le grade de docteur ès sciences naturelles. Mammalia, Series A. No.3860. Paris. $322 \mathrm{pp}$.

Jouffroy F.-K., Lessertisseur J., Saban R. \& SouteyrandBoulenger J.D. 1971. Mammifères. Musculature des membres, musculature peaucière, musculature des monotrèmes. Arthrologie // Traité de Zoologie. Anatomie, Systématique, Biologie. T.16. Fasc.3. P.1-476. 
Lewis O.J. 1989. Functional Morphology of the Evolving Hand and Foot. Oxford: Clarendon Press. 355 pp.

McMurrich. 1907. The phylogeny of the plantar musculature // American Journal of Anatomy. Vol.6. P.407-437.

Naples V.L. 1999. Morphology, evolution and function of feeding in the giant Anteater (Myrmecophaga tridactyla) // Journal of Zoology. Vol.249. P.19-41.

Redford K.H. 1985. Feeding and food preferences in captive and while giant anteaters (Myrmecophaga tridactyla) // Journal of Zoology. Vol.205. P.559-572.

Ruge G. 1878a. Zur vergleichenden Anatomie der tiefen Muskeln in der Fuss sohle // Morphologische Jarbuch. Bd.4. S.644-659.

Ruge G. 1878b. Untersuchung über die Extensorengruppe am Unterschenkel und Fuss der Säugethiere // Morphologische Jarbuch. Bd.4. S.592-643.

Shaw J.H., Carter T. S. \& Machado-Neto J.C. 1985. Ecology of the giant Anteater Myrmecophaga tridactyla in Serra da Canastra, Minas Gerais, Brazil: a pilot study. In Mont- gomery G.G. (ed.). The Evolution and Ecology of Armadillos, Sloths and Vermilinguas. Washington: Smithsonian Institution Press. P.379-384.

Shaw J.H., Machado-Neto J.C. \& Carter T. S. 1987. Behavior of free-living anteaters (Myrmecophaga tridactyla) // Biotropica. No.19. P.255-259.

Sinelnikov R.D. 1952. [Human Anatomy Atlas]. T.1. Moskva: Medgiz. 630 pp. [in Russian]

Windle B.C. \& Parsons F.G. 1898. On the myology of the terrestrial Carnivora. Part II // Proceeding of the Zoological Society of London. P.152-186.

Windle B.C. \& Parsons F.G. 1899. On the myology of the Edentata // Proceeding of the Zoological Society of London. P.990-1017.

Young R.J., Coelho C.M. \& Wieloch D.R. 2003. A note on the climbing abilities of giant anteaters, Myrmecophaga tridactyla (Xenarthra, Myrmecophagidae) // Boletim do Museu de Biologia Mello Leitão (N. Sér.). No.15. P.41-46. 